\title{
PREVALENCE OF BRUCELLOSIS IN DAIRY CATTLE IN ORGANIZED AND SMALLHOLDER FARMS IN SOME SELECTED AREAS OF BANGLADESH
}

\author{
M. A. S. Sarker*, M. S. Rahman, M. T. Islam, A. K. M. A. Rahman, M. B. Rahman ${ }^{1}$ and M. F. Rahman ${ }^{2}$ \\ Department of Medicine and ${ }^{1}$ Department of Microbiology \& Hygiene, Bangladesh Agricultural University, \\ Mymensingh-2200, Bangladesh, ${ }^{2}$ Director Mymensingh Medical College Hospital, Mymensingh
}

\begin{abstract}
Brucellosis causes a great economic loss to the livestock industries through abortion, infertility, birth of weak and dead off spring, increased calving interval and reduction of milk yield and it is endemic in Bangladesh. In this study we collected milk and blood samples simultaneously from 533 cows of Central Cattle Breeding and Dairy Farm, Savar, Dhaka and different Upazilas of Gaibandha and Mymensingh District. Five hundred thirty three samples were examined for antibodies to Brucella using the Milk Ring Test (MRT) and Rose Bengal Test (RBT). Overall $2.62 \%$ of milk samples were positive according to MRT, while $2.06 \%$ of the serum samples were positive to the RBT. Only $6(1.13 \%)$ of the samples were positive for both test (MRT and RBT). Out of 312 samples only $10(3.20 \%)$ were positive to MRT while $8(2.06 \%)$ were positive to RBT in Holstein Friesian cross $(\mathrm{p}>0.05)$ on the other hand out of 221 samples only $4(1.80 \%)$ were positive to MRT while $3(1.35 \%)$ were positive to RBT in Sahiwal cross. The prevalence of brucellosis was significantly higher in the age group of $>5$ years than other age groups $(\mathrm{p} \leq 0.01)$ on both test (MRT 2.75\% and RBT 2.25\%).Based on parity, significantly higher prevalence (MRT $2.93 \%$ and RBT 2.44\%) of MRT and RBT were obtained in parity 3-5 in comparison to other parity group (p $\leq 0.01$ ). It is, however, obvious that although the MRT is 1st-line screening tests for brucellosis in cows in some countries, their lack of specificity is of concern. Therefore, the requirement for other confirmatory tests that are more specific should be used for the diagnosis of the disease, especially in Bangladesh.
\end{abstract}

Key words: Brucellosis, Cows, Breed, Age, Parity, Zoonosis, MRT, RBT, Diagnosis, Serology

\section{INTRODUCTION}

Brucellosis is a disease of domestic and wild animals that can be transmitted to human. Brucellosis is a recognized public health problem with worldwide distribution and one of the major causes of morbidity. The Brucella species especially Brucella melitensis and Brucella suis are potential agents of biological terrorism (Meslin, 1997 and Wright, 2001). A high prevalence in certain geographic areas is well recognized, although largely underestimated. Brucellosis causes a great economic loss to the livestock industries through abortion, infertility, birth of weak dead offspring, increased calving interval and reduction of milk yield and it is endemic in Bangladesh (Roth et al., 2003). Brucellosis is a major zoonosis caused by small non motile gram negative and intracellular Cocco bacilli belonging to the genus Brucella. Brucella spp are facultative intracellular bacteria causing chronic disease which may persist for the whole of the affected organism. In animals brucellosis affects reproduction, fertility and reduces newborns survival and also milk productions. The mortality in adult animals is insignificant (Sewel and Blocklesby, 1990). In human the symptoms of brucellosis are weakness, joint and muscle pain, headache, undulant fever, hepatomegaly, splenomegaly, night sweats and chills marked asthenia and anorexia (Huge-Jones, 2000). Brucellosis is endemic in Bangladesh (Amin et al., 2005; Rahman et al., 2006; Uddin and Rahman, 2007; Nahar and Ahmed, 2009; Rahman et al., 2009, 2010, 2011; Ahasan et al., 2010). In order to control and eradicate brucellosis from human and livestock, it is very essential to establish an appropriate serological method for diagnosis of brucellosis in endemic areas. The classical serological test like MRT and RBT are known to produce cross reaction with other gram negative bacteria having antigenic similarities with brucella (Kittelrberger et al., 1988) and therefore produce a lot of false positive reaction. Every year a lot of undiagnosed cases of abortion, stillbirth and retained placenta are reported in cattle of Bangladesh which might be caused by Brucella.

Despite preventive and control measures that exist in developing state, there is still a high potential for transmission and spread of Brucella spp.via animals and their products and bye-products imported from these countries (Acha et al., 1987). Prevalence of brucellosis in cattle might constitute a significant hurdle for the

*Corresponding e-mail address: sayeedsarker68@gmail.com

Copyright (C) 2014 Bangladesh Society for Veterinary Medicine 


\section{A. S. Sarker and others}

development of livestock in Bangladesh. So early and accurate diagnosis is important for under taking an effective control measure against brucellosis. The MRT and RBT are widely used for screening of brucellosis exclusively in eradication programs (Sarker et al., 2014). The RBT is a simple agglutination technique. Because this test does not need special laboratory facilities and is simple and easy to perform, it is used to screen sera for antibodies to Brucella (Cadmas et al., 2008). These tests were chosen because they are less cumbersome to perform on a large scale and/or require no special equipment and expertise compared with other commonly used assays such as CFT and ELISA. Therefore the present study was undertaken to know the prevalence of brucellosis in cattle in organized and smallholder dairy farms in some selected areas of Bangladesh.

\section{MATERIALS AND METHODS}

As serological samples, venous blood samples were collected from jugular vein aseptically from sexually matured cattle of female sexes. A total of 533 blood samples were collected from cows of Central Cattle Breeding and Dairy Farm, Savar, Dhaka and all upazilas of Mymensingh and Gaibandha district of Bangladesh (Table 1). Milk samples were also collected from the same cows. At the time of sampling, questionnaire based data on age, sex, Breeds, location, calving status, disease history, parity were recorded. The Milk Ring Test (MRT) and Rose Bengal Test (RBT) were performed with the milk and blood samples respectively as screening tests for brucellosis. Brucella abortus strain 1119-3 (Dae Sung Microbiological lab, South Korea) were used for RBT.

\section{Rose Bengal Test ( RBT)}

The RBT was performed according to the procedure as described by Uddin et al. (2007). The test serum samples Brucella abortus antigen (William James House, Cowley Rd. Cambridge, CB4 OWX, UK) were kept 1 hour in room temperature before beginning the test. $30 \mu \mathrm{l}$ of each serum to be tested was placed on a glass plate circled approximately $2 \mathrm{~cm}$ in diameter. Then the vial of antigens was shaked gently and $30 \mu 1$ of antigen put beside each of the sera. The antigen and serum was mixed on the plate with a stirrer and spread over the area enclosed by the circle. Then the plate was placed on a mechanical rotator at $80-100 \mathrm{rpm}$ for 4 minutes and the reading was taken immediately. Any agglutination or precipitation was considered as positive, whereas no reaction indicated the absence of Brucella antigen in the sera (Fig. 1).

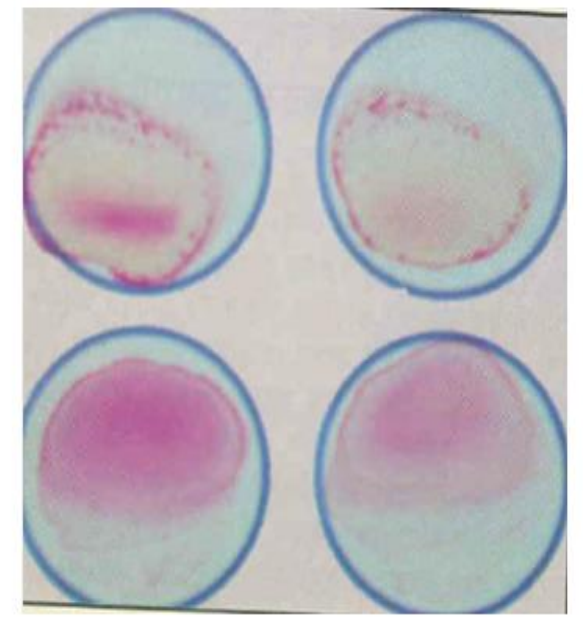

Fig. 1. Rose Bengal Test (RBT). Upper row positive and lower row.

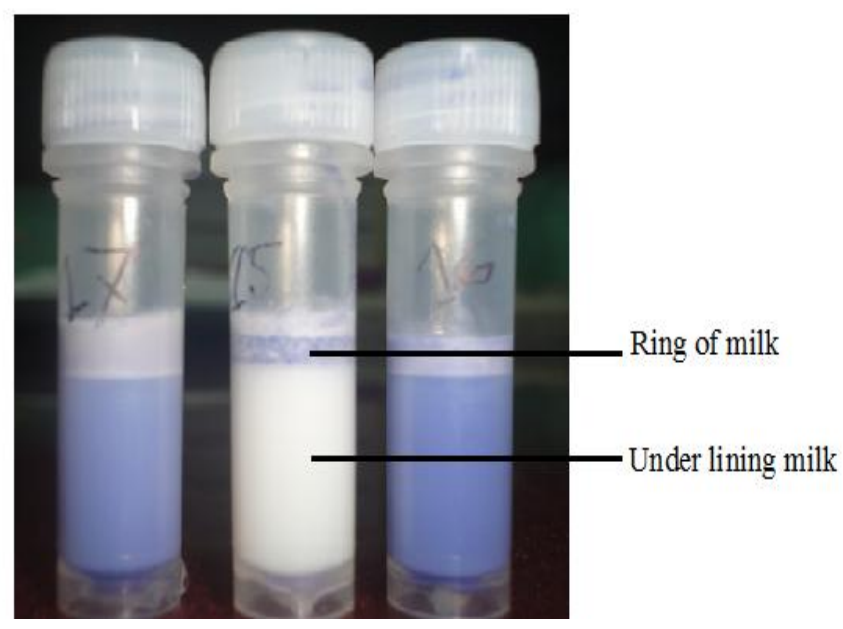

Fig. 2. Milk Ring Test. Milk in the middle tube indicates positive result showing ring of cream more colored than underlying milk. Milk in the two corner tubes indicate negative result shows ring of cream less colored than underlining milk. 


\section{Milk Ring Test (MRT)}

Milk Ring test was performed by following the manufacturer's instruction (National Veterinary Services Laborotories, USDA, Ames, Iowa). In brief, antigen was kept at room temperature $\left(18-23^{\circ} \mathrm{c}\right)$ for 1 hour before starting the test. After proper mixing, $1.0 \mathrm{ml}$ of milk sample and $50 \mu \mathrm{l}$ of MRT of antigen was added in each tube. The milk and MRT reagent was mixed with vortex and incubated for 1 hour at $+37^{\circ} \mathrm{c}$ and then between $+2{ }^{\circ} \mathrm{C}$ to $+8{ }^{\circ} \mathrm{C}$ for 18 to 20 hours. The result was read as positive if the ring of cream equally or more colored than the underling milk and as negative if the ring of cream less colored than the underlying milk (Fig. 2).

\section{Statistical analysis}

The Chi-square test $\left(\mathrm{x}^{2}\right)$ was performed to find out the relationship between the prevalence of brucellosis and demographic variables of cows.

\section{RESULTS}

Blood samples and milk samples were collected from 533 cows from Central Cattle breeding and Dairy Farm, Savar, Dhaka and all upazilas of Gaibandha and Mymensingh Districts of Bangladesh. Out of 533 samples 14 milk samples $(2.62 \%)$ and 11 serum samples $(2.06 \%)$ were positive milk and serum screened according to MRT and RBT respectively (Table 2 ). Six samples $(1.13 \%)$ were positive in both the tests like MRT and RBT. The highest positive rate of $3.20 \%$ was obtained among the Holstein Friesian cross of cows using MRT, while the highest positive rate of $2.56 \%$ obtained among the Holstein Friesian cows using RBT (Table 2). Age-wise prevalence of brucellosis based on MRT and RBT were $2.26 \%$ and $1.50 \%$ respectively in 1-4 years age group. On the other hand prevalence of brucellosis based on MRT and RBT were significantly higher $(2.75 \%$ and $2.25 \%$ ) in $>5$ years age group ( $\mathrm{p} \leq 0.01)$ than those of other age group (Table 3 ). Based on parity, significantly higher prevalence $2.93 \%$ and $2.44 \%$ of MRT and RBT were obtained respectively in parity 3-5 in comparison to other parity group $(\mathrm{p} \leq 0.01)$ (Table 3$)$.

Table 1. Milk and sera samples collected from CCB \& DF Gaibandha and Mymensingh District

\begin{tabular}{|llll|}
\hline & & \multicolumn{2}{c|}{ No of sample collected } \\
\cline { 3 - 3 } & Study area & Blood Sample & Milk sample \\
\hline & Mymensingh Sadar & 120 & 120 \\
& Muktagacha & 82 & 82 \\
& Phulbaria & 21 & 21 \\
& Trishal & 23 & 23 \\
& Valuka & 13 & 13 \\
& Guforgoua & 15 & 15 \\
& Isorgonj & 11 & 11 \\
& Gouripur & 18 & 18 \\
& Nandaiyl & 22 & 22 \\
& Haluaghat & 12 & 12 \\
& Dhobaura & 30 & 30 \\
& Taracanda & 25 & 25 \\
& Phulpur & 26 & 26 \\
& Gaibandha Sadar & 22 & 22 \\
& Palashbari & 10 & 10 \\
& Sundarganj & 24 & 24 \\
& Gobindogonj & 12 & 12 \\
& Shaghata & 12 & 12 \\
Gaibandha District & Sadullapur & 11 & 11 \\
& Phulceri & 14 & 14 \\
& & 10 & 10 \\
& & $\mathbf{5 3 3}$ & $\mathbf{5 3 3}$ \\
\hline
\end{tabular}

CCB \& D F- Central Cattle Breeding and Dairy Farm, Savar, Dhaka 


\section{A. S. Sarker and others}

Table 2. Breed wise prevalence of brucellosis based on MRT and RBT in cattle

\begin{tabular}{|lllllll|}
\hline Breeds of cattle & $\begin{array}{l}\text { No of } \\
\text { cows } \\
\text { tested }\end{array}$ & $\begin{array}{l}\text { MRT } \\
\text { positive }\end{array}$ & $\begin{array}{l}\text { Prevalence } \\
\text { on MRT \% }\end{array}$ & $\begin{array}{l}\text { RBT } \\
\text { positive }\end{array}$ & $\begin{array}{l}\text { Prevalence on } \\
\text { RBT \% }\end{array}$ & $\begin{array}{l}\text { Level of } \\
\text { significance }\end{array}$ \\
\hline $\begin{array}{l}\text { Holstein } \\
\text { Friesian cross }\end{array}$ & 312 & 10 & 3.20 & 8 & 2.56 & \\
$\begin{array}{l}\text { Sahiwal cross } \\
\text { Total }\end{array}$ & 221 & 4 & 1.80 & 3 & 1.35 & NS \\
\hline
\end{tabular}

NS=Non-significant $(\mathrm{p}>0.05)$

Table 3. Age and parity-wise prevalence of brucellosis in cattle based on MRT and RBT

\begin{tabular}{|llllllll|}
\hline Parameter & & $\begin{array}{l}\text { No of } \\
\text { cows } \\
\text { tested }\end{array}$ & $\begin{array}{l}\text { MRT } \\
\text { positive }\end{array}$ & $\begin{array}{l}\text { Prevalence } \\
\text { on MRT \% }\end{array}$ & $\begin{array}{l}\text { RBT } \\
\text { positive }\end{array}$ & $\begin{array}{l}\text { Prevalence } \\
\text { on RBT \% }\end{array}$ & $\begin{array}{l}\text { Level of } \\
\text { significance }\end{array}$ \\
\hline Age & 1-4 years & 133 & 3 & 2.26 & 2 & 1.50 & $* *$ \\
& $>5$ years & 400 & 11 & 2.75 & 9 & 2.25 & $* *$ \\
Parity & $1-2$ & 123 & 2 & 1.63 & 1 & 0.81 & $* .44$ \\
\end{tabular}

** Significant at $\mathrm{p} \leq 0.01$

\section{DISCUSSION}

The overall prevalence of brucellosis based on MRT and RBT was recorded as $2.62 \%$ and $2.06 \%$, respectively. The MRT is generally used for screening; other tests are required for confirmatory diagnosis. This is an agreement with Morgan (1967) who stated that the test should be used in conjunction with the established tests and not instead of them. The higher prevalence by MRT might result from false positive which could be due to many causes including mastitis, colostrums, collection at the end of lactation period or a hormonal disorder (Bercovich and Moerman, 1979). Carefully samples were collected from dairy cows excluding mastitis infected and recently delivered cows to avoid false positive reactions. It has been shown that different serological tests used for the diagnosis of brucellosis vary considerably in their ability to detect anibodies of a particular immunoglobulin class. Infected animals may or may not produce all antibody isotypes in detectable quantities (FAO, 2004). Vaccination against brucellosis is not carried out in Bangladesh, so that our result may reflect natural infection. In general the MRT have been shown in other studies to have high sensitivity but lower specificity. The MRT is not normally used on individual animals because of false positives (less specifity).

Based on outcome of the study, it is suggested that although MRT and RBT are generally useful for screening for brucellosis especially in developing countries where other tests are cumbersome to perform on a large scale and require special equipment and expertise these tests still have limitations where vaccination or medical records are not available. As a result of these limitations other confirmatory tests like ELISA, CFT, SAT shall be carried out in conjunction with MRT and RBT due to confirm the brucellosis status of cattle in Central Cattle Breeding and Dairy Farm, Savar, Dhaka and Different Upazilas of Gaibandha and Mymensingh District. The ELISA is an available assay for use on milk and serum and is very useful where large number of samples require testing. Milk ELISA is used on pooled samples which is more cost effective than testing individual animals. Although these tests may be very expensive they are needed to confirm the brucellosis status of cattle in our study area in order to safeguard the general public and in particularly that of the people directly involved in the meat inspection, milk collectors and meat milk processing. The older animal supposed to be more infected because of more contact with infectious agents and sometimes become more susceptible from malnutrition during pregnancy. It appears that the prevalence of infection in animals more than 5 years of age compared to younger animals and higher prevalence of brucellosis among older cows might be related to maturity with the advancing age. Seropositivity to be considered due to natural infection occurred because vaccination in cows has never been practiced in Bangladesh. The prevalence and severity of disease may vary with the breed, geographic location, types of diagnostic tests, husbandry and environmental factor as well as the biovar of the organism. 


\section{REFERENCES}

1. Acha PN and Szyfres B (1987). Zoonoses and communicable diseases common to man and animals ( $2^{\text {nd }}$ edn). Scientific Publication No. 503, Pan American Health Organization, Washington DC.

2. Amin KMR, Rahman MB, Rahman MS, Han JC, Park JH and Chae JS (2005). Prevalence of brucella antibodies in sera of cows in Bangladesh. Journal of Veterinary Science 6: 223-226.

3. Ashan MS, Rahman MS and Song HJ (2010). A sero-prevalence of brucella spp. Antibodies and individual risk factors of infection in cattle of Bangladesh. Korean Journal of Veterinary Service 33: 121-128.

4. Bercovich Z and Moerman A (1979). Non specific positive milk ring test(s) in tank milk and Estrumater in the treatment of cattle. Tijdschrift voor Diergeneeskunde 104: 713-716.

5. Cadmus SIB, Adesokan HK and Stack J (2008). The use of milk ring test and rose Bengal test in brucellosis control and eradication in Nigeria. Journal of the South African Veterinary Association 79 (3): 113-115.

6. Food and Agriculture Organisatio of theunited Nations (2004). Bovine brucellosis. Animal health/disease cards.

7. Hugh-Jones ME (2000). Zoonoses, Recognition, Control and Prevention. $1^{\text {st }}$ edited by Huge-Jones, ME, Hubbert, WT and Hagstad HV, A Blackwell Publishing Company, Iowa State Press, p. 7.

8. Kittelberger R, Bundesen PG, Cloeckaert A, Greiser Wil ke I, Letesson JJ (1998). Serological cross-reactivity between Brucella abortus and Yersinia enterocolitica 0.9: IV. Evaluation of the $\mathrm{M}$ and $\mathrm{C}$ epitope antibody response for the specific detection of B abortus infections. Veterinry Microbiology 60: 45-57.

9. Meslin FX (1997). Global aspects of emerging and potential zoooses: a WHO perspective," Emerging Infectious Diseases, vol. 3 supplements 2, p. 223-228.

10. Morgan WJB (1967). The serological diagnosis of bovine brucellosis. Veterinary Record 80: 612-621.

11. Nahar A and Ahmed MU (2009). Sero-prevalence study of brucellosis in cattle and contact human in Mymensingh District. Bangladesh Journal of Veterinary Medicine 7: 269-274.

12. Rahman MS, Alam N, Rahman AKHA, Huque AKMF, Ahasan MS and Song HJ (2009). Sero-prevalence of specific brucella infection of cattle in Bangladesh Agricultural University Veterinary Clinics and its surrounding areas. Korean Journal of Veterinary Services 32 (3): 219-225.

13. Rahman MS, Faruk MO, Her M, Kim JY, Kang SI and Jung HC (2011). Prevalence of brucellosis in ruminants in Bangladesh. Veterinary Medicine 56 (8): 379-385.

14. Rahman MS, Haque MF, Ahasan MS and Song HJ (2010). Indirect enzyme linked Immunosorbent assay for the diagnosis of brucellosis in cattle. Korean Journal of Veterinary Service 32 (2): 113-119.

15. Rahman MS, Han HC, Park J, Lee HJ, Eo SK and Chae JS (2006). Prevalence of brucellosis and its association with reproductive problems in cows in Bangladesh. Veterinary Record 159: 180-182.

16. Roth F, Zinntag J, Orkhon D, Chimed-Ochir G, Hutton G (2003). Human health benefit from vaccination for brucellosis: case study. Bulletin World Health Organization 81: 867-876.

17. Sarker MAS, Rahman MS, Islam MT, Rahman AKMA, Rahman MB, Akter L and Chaki A (2014). The use of milk ring test for control and eradication of brucellosis in Bangladesh. $2^{\text {nd }}$ International Exhibition on Dairy, Aqua \& Pet Animal p. 144-147.

18. Sewel MMM and Blocklesby DW (1990). Animal Disease in the Tropics. Bailliere Tindall, London, p. 385.

19. Uddin MJ and Rahman MS (2007). Brucellosis in goat in Bangladesh. Journal of Bangladesh Agricultural University 5: 287-294.

20. Wright SG (2001). Brucellosis, in Manson's Tropical Diseases. G Cook, Edn, p. 886-891, Harcourt (India) Private Limited, New Delhi, India, $20^{\text {th }}$ edition. 